\title{
Propriedades físicas de solo em Floresta Ombrófila Mista sob processo de restauração passiva
}

\author{
Soil physical properties in Mixed Ombrophilous Forest under passive \\ restoration process
}

\section{Iris Cristina Bertolini ${ }^{1}$, Ana Paula Vantroba ${ }^{1 *}$, Talyta Mytsuy Zanardini Galeski Sens ${ }^{1}$, Cristiane Dalagua Paier ${ }^{2}$, Cristiano Andre Pott ${ }^{1}$ e Luciano Farinha Watzlawick ${ }^{1}$}

\begin{abstract}
Resumo
Este trabalho avaliou as propriedades físicas do solo em áreas de floresta em sucessão secundária e em processo de restauração passiva. As áreas pertencem à Universidade Estadual do Centro-Oeste do Paraná, Guarapuava. O delineamento experimental foi inteiramente casualizado, com amostras em seis pontos de cada área, nas profundidades de: 0 - 0,1 m, 0,1 - 0,2 $\mathrm{m}$ e 0,2 - 0,3 $\mathrm{m}$. A floresta em sucessão secundária obteve maior quantidade de matéria orgânica, esta propriedade atua diretamente nas demais variáveis avaliadas. A área em restauração passiva obteve maiores valores para a densidade do solo, menor porosidade total nas três profundidades e maior resistência à penetração do solo, sendo que estes resultados estão ligados ao histórico de uso da área. A microporosidade não diferiu entre as áreas estudadas e a macroporosidade apresentou menores valores com diferença apenas na camada de 0,2 - 0,3 m, pela presença de raízes e decomposição da serapilheira. O maior valor da densidade máxima foi na área em restauração passiva $\left(1,23 \mathrm{Mg} \mathrm{m}^{-3}\right)$, com umidade de $0,32 \mathrm{Mg} \mathrm{Mg}^{-1}$, já na área de floresta em sucessão secundária esse valor foi de $1,12 \mathrm{Mg} \mathrm{m}^{-3}$ e umidade de $0,45 \mathrm{Mg} \mathrm{Mg}^{-1}$, em função da quantidade de matéria orgânica que influencia diretamente na redução da densidade. A recuperação do solo em áreas degradadas é um processo lento, e mesmo após dez anos, não foi possível restabelecer as propriedades físicas ideais na floresta sob restauração passiva.
\end{abstract}

Palavras-chave: Solos florestais, estrutura do solo, Latossolo Bruno, floresta em regeneração.

\begin{abstract}
The objective was to evaluate the physical properties of the soil in forest areas in secondary succession and in the process of passive restoration. The areas belong to the State University of the Midwest of Paraná, Guarapuava, Brazil. The experimental design was completely randomized, with samples at six points in each area, at depths of $0-0.1 \mathrm{~m}, 0.1-0.2 \mathrm{~m}$ and $0.2-0.3 \mathrm{~m}$. The forest in secondary succession had a greater amount of organic matter, this property acts directly on the other evaluated variables. The area under passive restoration had higher values for soil density, lower total porosity at the three depths and greater resistance to soil penetration, and these results are related to the history of area use. The microporosity did not differ between the studied areas and the macroporosity presented smaller values with only difference in the layer of $0.2-0.3 \mathrm{~m}$, due to the presence of roots and decomposition of the litter. The highest value of maximum density was in the area under passive restoration (1.23 $\left.\mathrm{Mg} \mathrm{m}^{-3}\right)$, with humidity of $0.32 \mathrm{Mg} \mathrm{Mg}^{-1}$, already in the area of forest in secondary succession this value was $1.12 \mathrm{Mg} \mathrm{m}^{-3}$ and humidity of $0.45 \mathrm{Mg} \mathrm{Mg}^{-1}$, depending on the amount of organic matter that directly influences the reduction of the density. Soil recovery in degraded areas is a slow process, and even after ten years, it was not possible to restore the ideal physical properties in the forest under passive restoration.
\end{abstract}

Keywords: Forest soils, soil structure, Oxisol, forest regeneration.

\section{INTRODUÇÃO}

As propriedades físicas do solo são responsáveis por determinar as condições de disponibilidade de água, aeração, infiltração e capacidade produtiva de um ecossistema (BOGNOLA et al., 2010). Entretanto, a ação antrópica promove alterações nessas propriedades, na maioria das vezes causando impacto ambiental negativo (SILVA et al., 2007).

\footnotetext{
1. Universidade Estadual do Centro-Oeste - UNICENTRO. Guarapuava, PR, Brasil.

2. Universidade Federal da Grande Dourados - UFGD. Dourados, MS, Brasil.

* Autor Correspondente: paulavantroba@hotmail.com
} 
Os níveis de alteração do solo, podem ser avaliados comparando áreas em estado natural, sem atividade antrópica, como uma área de floresta preservada (CALGARO et al., 2015), com a qualidade e as propriedades físicas de outros ecossistemas (ANDREOLA et al., 2000). Pois, os ambientes naturais apresentam integração harmoniosa entre a cobertura vegetal e as propriedades físicas do solo, em função dos processos essenciais de ciclagem de nutrientes, do acúmulo e decomposição da matéria orgânica (CARDOSO et al., 2011).

A conversão de florestas em sistemas agrícolas ou pastagens, induzem a compactação do solo, devido ao pisoteio animal, tráfego de máquinas e intensificação no uso da terra (HAMZA; ANDERSON, 2005). Portanto, o desmatamento para a expansão da fronteira agrícola e pecuária, reduz a qualidade e o potencial produtivo do solo tornando-o degradado, decorrente da baixa capacidade de armazenamento de água, suscetibilidade à erosão e redução da capacidade de armazenar carbono (COUTINHO et al., 2017).

Uma floresta que passou pelo processo de retirada parcial ou total da vegetação primária, seja por ações antrópicas ou causas naturais, resultam na formação de florestas com vegetação secundária (CONAMA, 1993), devido ao processo de regeneração natural.

Em casos onde a regeneração natural tem dificuldades de se desenvolver, uma alternativa para a recuperação dessas áreas degradadas, é o plantio de mudas, pois, as árvores são capazes de promover o armazenamento e manutenção de água no solo, reduzindo o escoamento superficial que possibilita a prevenção da erosão pela formação de agregados, atuando na conservação dos solos (SERENGIL et al., 2007).

A restauração florestal pode ser definida como um processo de restabelecimento de um ecossistema, de maneira que se obtenham características semelhantes às áreas naturais (REIS et al., 2014), e é baseada em duas linhas principais: a restauração passiva, relacionada a presença de espécies que atuam na formação do banco de sementes e plântulas no solo, sendo mais eficiente em áreas onde ocorre cobertura vegetal (MARTINS, 2014), e a restauração ativa, que envolve a intervenção humana, auxiliando na redução do tempo necessário para a ocorrência da regeneração natural (AIDE, 2000).

Uma vez que, o processo de restauração de um sistema deve priorizar não somente o restabelecimento da estrutura vegetal, mas principalmente a recuperação de características ecológicas da comunidade que facilitem o seu desenvolvimento natural, por exemplo, as propriedades físicas do solo (TRENTIN et al., 2018).

Dessa forma, o objetivo do trabalho foi avaliar as propriedades físicas do solo de uma floresta em processo de restauração e em uma floresta em sucessão secundária em um Latossolo Bruno, no município de Guarapuava, PR, e verificar correlação entre elas. A hipótese desta pesquisa é que as propriedades físicas do solo são recuperadas após 10 anos de restauração passiva em uma Floresta Ombrófila Mista.

\section{MATERIAL E MÉTODOS}

\section{Área de estudo}

Este estudo foi desenvolvido na Universidade Estadual do Centro-Oeste (UNICENTRO), Campus CEDETEG, no município de Guarapuava, estado do Paraná. A área está localizada entre as coordenadas geográficas: $25^{\circ} 23^{\prime} 15^{\prime \prime}$ de latitude sul (S) e $51^{\circ} 29^{\prime} 24^{\prime \prime}$ de longitude Oeste (W), e altitude de aproximadamente 1033 metros.

O clima é do tipo Subtropical Úmido Mesotérmico, classificado como Cfb, com ocorrência de verões com temperatura amena, chuvas bem distribuídas e sem estação seca definida (ALVARES et al., 2013), e precipitação média anual de 1961 mm (THOMAZ; VESTENA, 2003).

O solo da área de estudo foi classificado por Michalowicz (2012) como Latossolo Bruno distrófico muito argiloso. A Tabela 1, apresenta as características químicas do solo da floresta em restauração (FR) e da floresta natural (FN), na camada de $0-0,3 \mathrm{~m}$ de profundidade.

O estudo foi realizado em duas áreas de floresta, sendo FS com aproximadamente 11,5 ha, caracterizada pela Floresta Ombrófila Mista Aluvial (IBGE, 2012). A área de FR encontra-se em processo de restauração passiva induzida, com aproximadamente 10 anos e área de 1 ha, tendo histórico de uso e ocupação do solo por pastagem, onde em 2007, foi realizado o plantio de mudas, para dar início ao processo de restauração, pois devido ao alto nível de degradação naquele momento não era possível que a regeneração natural se desenvolvesse, vindo a ocorrer ao longo do período. 
Bertolini et al. - Propriedades físicas de solo em Floresta Ombrófila Mista sob processo de restauração passiva

Tabela 1. Características químicas e granulometria dos solos da floresta em restauração e da floresta em sucessão secundária na camada de 0 a 0,3 m.

Table 1. Chemical characteristics and granule measures of forest soils in restoration and forest in secondary succession in the 0 to $0,3 \mathrm{~m}$ layer.

\begin{tabular}{|c|c|c|c|c|c|c|c|c|c|c|}
\hline \multirow{2}{*}{ Área } & \multirow{2}{*}{$\begin{array}{c}\mathrm{pH} \\
\text { (SMP) }\end{array}$} & \multirow{2}{*}{$\begin{array}{c}\mathrm{pH} \\
(\mathrm{CaCl})\end{array}$} & \multirow{2}{*}{$\begin{array}{c}C \\
\mathrm{~g} \mathrm{dm}^{-3}\end{array}$} & \multirow{2}{*}{$\begin{array}{c}\mathrm{MO} \\
\mathrm{g} \mathrm{dm}^{-3}\end{array}$} & \multirow{2}{*}{$\begin{array}{c}\text { Bases } \\
\text { V\% }\end{array}$} & \multirow{2}{*}{$\begin{array}{c}P \\
\mathrm{mg} \mathrm{dm}^{-3}\end{array}$} & $\mathbf{K}$ & $\mathrm{Ca}$ & $\mathrm{Mg}$ & Al \\
\hline & & & & & & & \multicolumn{4}{|c|}{$\mathrm{cmol}_{\mathrm{c}} \mathrm{dm}^{-3}$} \\
\hline FR & 4,44 & 5,75 & 22,96 & 39,58 & 43,0 & 2,54 & 0,15 & 2,92 & 1,45 & 0,3 \\
\hline FS & 4,85 & 3,83 & 24,95 & 43,02 & 15,8 & 2,09 & 0,23 & 1,42 & 0,55 & 3,3 \\
\hline \multicolumn{11}{|c|}{ 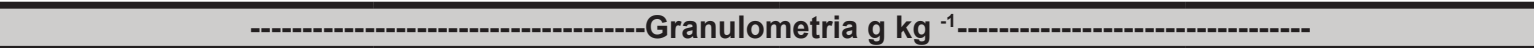 } \\
\hline \multicolumn{3}{|c|}{ Área } & \multicolumn{2}{|c|}{ Areia } & & \multicolumn{2}{|c|}{ Silte } & \multicolumn{3}{|c|}{ Argila } \\
\hline \multicolumn{3}{|c|}{ FR } & \multicolumn{2}{|c|}{46} & & \multicolumn{2}{|c|}{187} & \multicolumn{3}{|c|}{767} \\
\hline \multicolumn{3}{|c|}{ FS } & \multicolumn{2}{|c|}{52} & & \multicolumn{2}{|c|}{121} & \multicolumn{3}{|c|}{827} \\
\hline
\end{tabular}

Em que: FR= Floresta em Restauração; FS= Floresta em Sucessão Secundária; C= Carbono; MO= Matéria Orgânica; $\mathrm{P}=$ Fósforo (Mehlich I); K=Potássio, Ca= Cálcio; Mg= Magnésio; Al= Alumínio.

\section{Amostragem e análises de propriedades físicas do solo}

As variáveis estudadas para determinação das propriedades físicas do solo foram: densidade do solo (Ds), macroporosidade (Map), microporosidade (Mip), porosidade total (PT), capacidade de aeração total (CAT) e capacidade de campo (CC), densidade máxima de compactação (DMax), densidade relativa do solo (Dr) e resistência do solo à penetração (RP) em ambas as florestas.

Foram coletadas amostras de solo com estrutura preservada, utilizando os anéis metálicos de $100 \mathrm{~cm}^{3}$ com auxílio de macaco hidráulico (EMBRAPA, 2011). As coletas foram realizadas em seis pontos aleatórios em cada área, em cada ponto foi aberto uma trincheira com 0,5 $\mathrm{m}$ de comprimento, $0,4 \mathrm{~m}$ de largura e $0,30 \mathrm{~m}$ de profundidade, e foi retirada uma amostra em cada camada de 0 a $0,1 \mathrm{~m}$, 0,1 a $0,2 \mathrm{~m}$ e 0,2 a $0,3 \mathrm{~m}$ de profundidade.

Após as coletas, as amostras foram encaminhadas para o Laboratório de Solos da Universidade Estadual do Centro-Oeste - UNICENTRO, em Guarapuava - PR, onde foram submetidas à saturação por 48 horas e após foram levadas para a mesa de tensão. A Map foi definida por meio da diferença de volume de poros drenados entre o solo saturado e o potencial matricial de - $6 \mathrm{kPa}$. A Mip foi definida por meio da diferença de volume de poros drenados no potencial matricial de $-6 \mathrm{kPa}$ e o solo seco a $105^{\circ} \mathrm{C}$. A PT consiste no somatório da Map e Mip. A CAT foi definida por meio da diferença de volume de poros drenados entre o solo saturado e o potencial matricial de - $10 \mathrm{kPa}$ a CC foi definida por meio da diferença de volume de poros drenados no potencial matricial de $-10 \mathrm{kPa}$ e o solo seco a $105^{\circ} \mathrm{C}$, conforme descrito por Reynolds et al. (2002). A capacidade de armazenamento de ar e a capacidade de armazenamento de água foram calculadas por meio da relação entre CAT/PT e CC/PT, respectivamente. A Ds foi obtida segundo metodologia da EMBRAPA (2011).

A análise granulométrica foi realizada com amostras de terra fina seca ao ar (TFSA) peneiradas em malha de $2 \mathrm{~mm}$ das quais foram retirados 50 g para cada uma das amostras. A dispersão foi realizada com a utilização de dispersante químico (200 ml de $\mathrm{NaOH})$ seguida de agitação mecânica, através do método do densímetro para determinação do teor de argila, e o teor de areia foi obtido por peneiramento malha $0,053 \mathrm{~mm}$ e silte foi obtido por diferença, seguindo a metodologia da EMBRAPA (2011).

A mensuração da RP foi realizada com a utilização do penetrômetro eletrônico, o penetroLOG. Para cada ponto de coleta dos anéis foram realizadas 6 medições de penetrometria, totalizando 36 avaliações em cada área, até a profundidade de 0,5 m.

A DMax do solo foi obtida através da realização do teste de Proctor, normatizado pela Associação Brasileira de Normas Técnicas (NBR 182) (ABNT, 1986). Para cada área foram preparados aproximadamente $60 \mathrm{~kg}$ de solo, coletados por meio de amostra composta e peneirados em malha de 4,5 mm, posteriormente seco em temperatura ambiente durante sete dias.

Para cada ponto de umidade do ensaio de Proctor foram utilizados aproximadamente $6 \mathrm{~kg}$ de solo, sendo necessário $2 \mathrm{~kg}$ para cada repetição, totalizando três repetições por ponto para compor a média. Após a umidade do solo conhecida, para cada ponto foi adicionado aproximadamente $1000 \mathrm{ml}$ de água, e a cada nova medida foi adicionado mais $100 \mathrm{ml}$ de água para o solo da floresta em sucessão secundária e $150 \mathrm{ml}$ para o solo da floresta em restauração.

Posteriormente o solo umedecido foi colocado no cilindro em três camadas sucessivas, intercaladas com a aplicação de 26 golpes. Foi mensurado o peso do solo e do cilindro e uma amostra foi retirada 
para a obtenção da umidade em que o solo foi compactado. A partir do teste de Proctor foi possível determinar o valor da DMax de ambas as áreas, o qual foi utilizado para o cálculo da densidade relativa que é a razão entre a Ds determinada por meio dos anéis volumétricos e a DMax (KLEIN, 2014).

A Ds não fornece informações suficientes para quantificar o grau de compactação de um solo, desse modo têm sido utilizada a Dr, a qual possui limites reconhecidos para se considerar os níveis de compactação do solo (MARCOLIN e KLEIN, 2011).

\section{Análises de dados}

A análise estatística foi baseada em um delineamento inteiramente casualizado (DIC), em que as variáveis de Ds, Dr, Map, Mip, PT, CAT, CC, CAT/PT, CC/PT e RP, foram submetidos à análise de variância e as médias comparadas pelo teste t. Também foi realizada a análise de correlação de Pearson a $1 \%$ e $5 \%$ de probabilidade, com o propósito de se conhecer a correlação entre as variáveis, utilizando o Software Assistat v.7.7.

\section{RESULTADOS E DISCUSSÃO}

As curvas de compactação com o ensaio de Proctor mostram que a DMax foi maior na área de floresta em restauração 1,23 $\mathrm{Mg} \mathrm{m}^{3}$ com uma umidade ótima de $0,32 \mathrm{Mg} \mathrm{Mg}^{-1}$, enquanto que na área de floresta secundária a DMax foi de 1,12 $\mathrm{Mg} \mathrm{m}^{3}$ e umidade de $0,45 \mathrm{Mg} \mathrm{Mg}^{-1}$ (Figura 1).

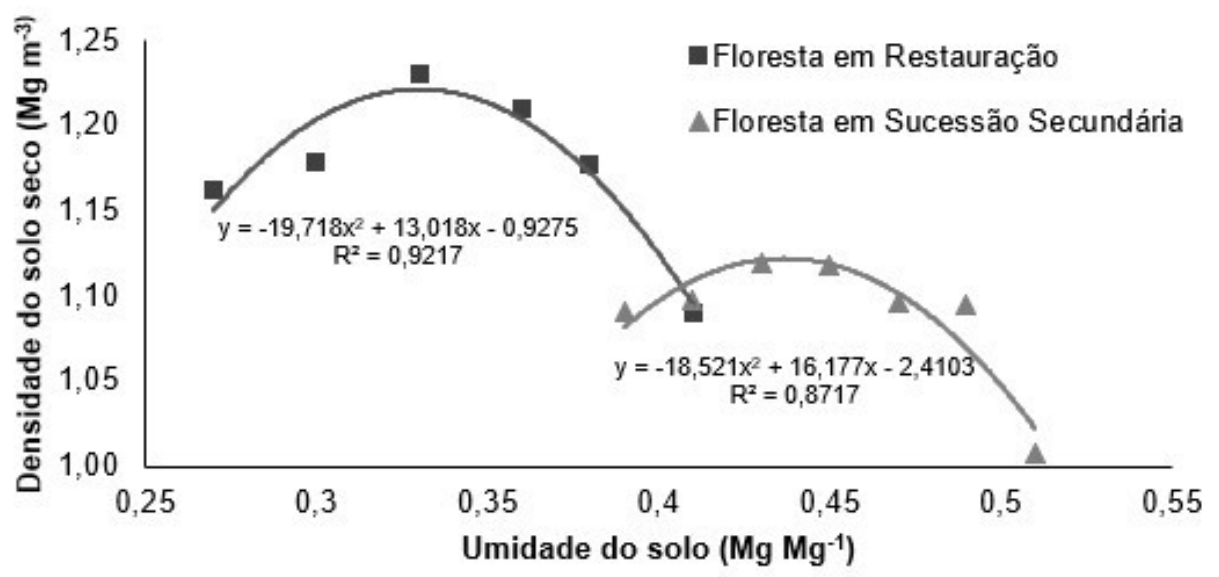

Figura 1. Curva da densidade máxima do solo em função da umidade, com ensaio de Proctor, na área de floresta em restauração e na floresta em sucessão secundária.

Figure 1. Maximum soil density related to humidity, with Proctor's test, in the forest area under restoration and in the secondary succession forest.

A diferença nos valores da DMax entre as duas áreas, pode estar relacionada com o histórico do uso e manejo realizados anteriormente na área de floresta em restauração, e estão relacionados com os altos teores da matéria orgânica na área de floresta secundária.

De acordo com Braida et al. (2006), a deposição de matéria orgânica no solo atua na redução da densidade máxima, pois apresenta baixa densidade em relação a dos sólidos minerais do solo, e auxilia positivamente na função estrutural, como foi verificado neste estudo em que a floresta em sucessão secundária apresentou maior teor de matéria orgânica e menor valor para a DMax que a floresta em restauração.

Entre a área de floresta em sucessão secundária e a área em restauração houve diferença significativa na densidade do solo nas camadas de 0 - 0,1 m, 0,1 - 0,2 m, e 0,2 - 0,3 m de profundidade. Nas três camadas avaliadas a área de floresta em sucessão secundária apresentou menor densidade do solo (Figura 2).

Essa diferença entre as áreas já era esperada, pois a área em restauração era utilizada com pastagem em alto grau de degradação, que influenciou na compactação do solo pelo pisoteio animal. Coutinho 

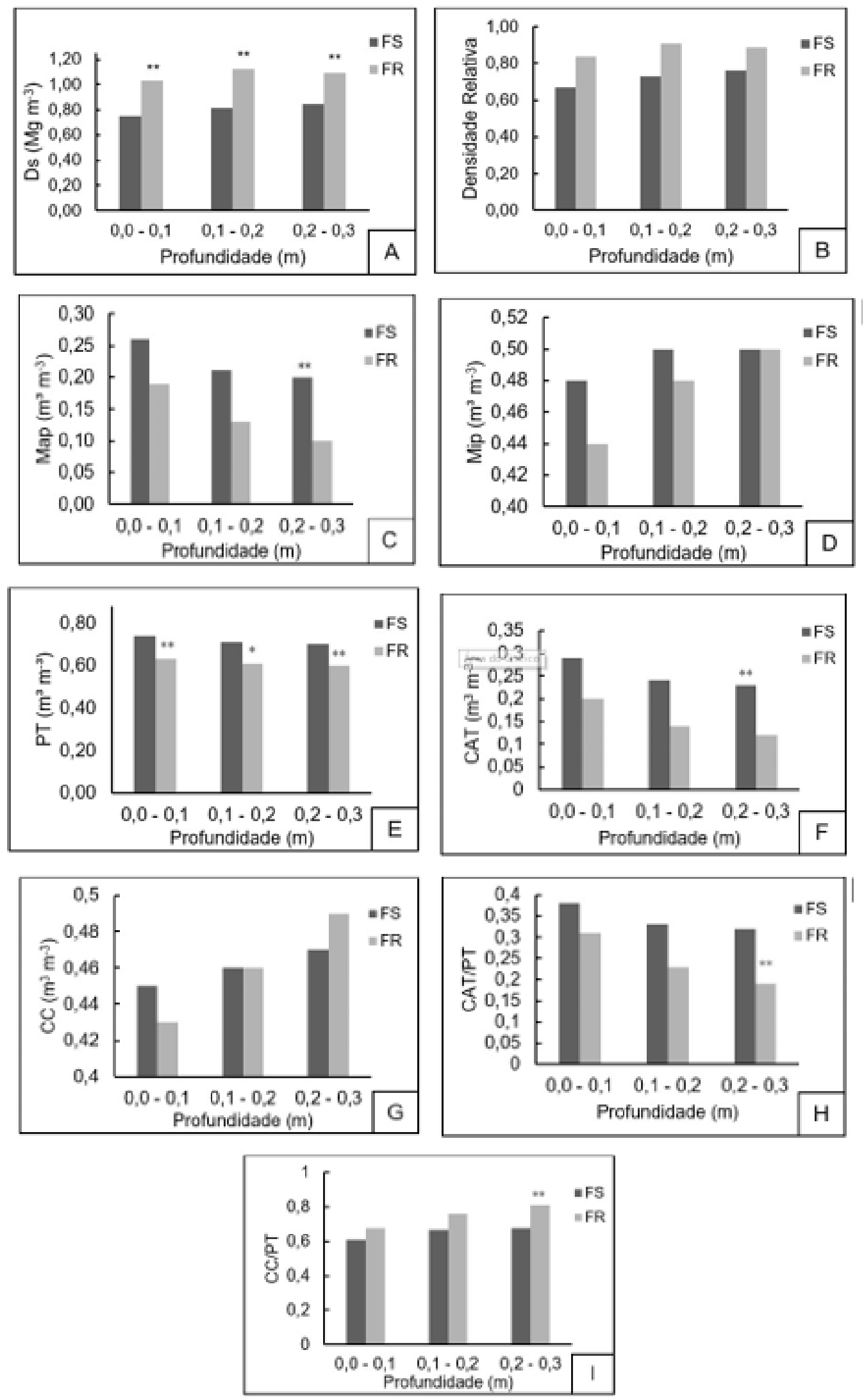

Em que: teste t a $5 \%$ de probabilidade $(*)$ e $1 \%$ de probabilidade $(* *)$.

Figura 2. (A) Valores de densidade do solo (Ds), (B) densidade relativa, (C) macroporosidade (Map), (D) microporosidade (Mip), (E) porosidade total (PT), (F) capacidade de aeração total (CAT), (G) Capacidade de campo (CC), (H) Capacidade de armazenamento de ar (CAT/PT) e (I) Capacidade de armazenamento de água (CC/PT) em área de floresta em sucessão secundária (FS) e área de floresta em restauração (FR).

Figure 2. (A) Values of soil density (Ds), (B) relative density, (C) macroporosity (Map), (D) microporosity (Mip), (E) total porosity (PT), (F) total aeration capacity (CAT), (G) water capacity (CC), (H) Air storage capacity (CAT/PT) and (I) Water storage capacity (CC/PT) in a forest area under secondary succession (FS) and a forest area in restoration (FR). 
(2017), afirma que a lentidão na recuperação das propriedades físicas do solo ocorre em função da compactação pelo pisoteio animal e manejo inadequado utilizado anteriormente.

Em ambas as áreas avaliadas a camada de 0 - 0,1 m, apresentou valores baixos de densidade do solo, o que pode ser atribuído ao elevado teor de matéria orgânica, que contribui para reduzir a densidade do solo por ser menos densa que a fração mineral (BORTOLINI et al., 2013). A menor densidade do solo em floresta nativa também foi verificada quando comparada com sistemas agroflorestais e cultivo convencional, atribuindo essa diferença ao elevado teor de carbono orgânico (DA SILVA et al., 2011).

A floresta em restauração apresentou o maior valor de Dr, de 0,91 na camada de 0,1 - 0,2 m, indicando que esta camada está compactada, pois segundo Reinert et al. (2008), o valor que indica se o solo está compactado situa-se entre 0,90 a 0,95 equivalente a 90 a 95\% do grau de compactação, situação em que ocorre restrição de crescimento radicular e deformações na morfologia das raízes. E para Reichert et al., (2007), a compactação do solo em áreas agrícolas e em pastagens ocorre geralmente em uma camada encontrada até no máximo a $20 \mathrm{~cm}$, enquanto, em áreas florestais a compactação pode atingir maiores profundidades.

Na floresta em sucessão secundária a Dr encontrada ficou entre 0,66 a 0,76 nas camadas de 0 - 0,1 e 0,2 - 0,3 m respectivamente. Esse resultado mostra a influência do alto teor da matéria orgânica, além do fato de não haver compactação do solo por máquinas agrícolas ou por animais. Klein (2006) em estudos em um Latossolo vermelho, observou que em condição de florestas naturais a densidade relativa apresentou valores entre 0,66 e 0,69. Para áreas de agricultura, Klein (2014) indica que valores de Dr abaixo de 0,80 ou $80 \%$ não estão compactados.

Luciano et al. (2012), encontraram Dr acima da densidade crítica em um Nitossolo Bruno distrófico típico, que são valores considerados prejudiciais para o desenvolvimento de cultivos anuais, podendo resultar limitações no crescimento das plantas. No entanto, não foram observados sintomas de limitação de crescimento do campo nativo, mostrando que esse tipo de vegetação consegue se desenvolver em solos com valores de Dr acima de 0,90. Segundo esses mesmos autores, ainda não existem estudos que indiquem Dr crítica, para solos sob vegetação de campo nativo ou floresta nativa que foram submetidos a algum processo de compactação, como pisoteio animal ou tráfego de máquinas.

Para a macroporosidade observou-se diferença significativa entre as áreas de floresta em sucessão secundária e a área em restauração apenas na camada de 0,2 - 0,3 m, em que a área de floresta em sucessão secundária apresentou maior volume de macroporos (Figura 2C). A deposição e a decomposição da serrapilheira na área em restauração, juntamente com o crescimento de espécies arbóreas, aliado com outras espécies que cresceram espontaneamente apresentando diversos sistemas radiculares, podem ter contribuído para elevar os teores de carbono do solo nas camadas superficiais, aumentando a quantidade de macroporos, pois a macroporosidade é formada através da união de agregados de maior tamanho, pelas forças eletrostáticas, pela atividade microbiana e crescimento de raízes (SPERA et al., 2008).

Coutinho et al. (2017), observaram um aumento dos valores de macroporosidade na camada de $0-0,4 \mathrm{~m}$, em função do tempo de regeneração das florestas secundárias e atribuíram à maior quantidade de carbono orgânico total na área mais antiga de floresta secundária, a qual também apresenta um tempo maior de regeneração da vegetação, criando-se um ambiente mais favorável à presença de organismos edáficos (MENEZES et al., 2009) e possibilitando a formação de bioporos que são canais para a circulação de água e ar no solo (HICKMANN et al., 2012).

Em relação a microporosidade, não houve diferença significativa entre os dois locais estudados (Figura 2D). Em estudo realizado por Coutinho et al. (2017), também não foi observado diferença na microporosidade do solo entre as áreas de fragmento de floresta secundária em estágio inicial e fragmento de floresta secundária em estágio intermediário. De acordo com os autores, essa ausência de diferença pode estar relacionada ao maior teor de argila e de carbono orgânico total.

Na porosidade total observou-se diferença estatística entre as áreas avaliadas (Figura 2E). A área de floresta em restauração apresentou menor porosidade total nas três camadas avaliadas. De acordo com Brady e Weil (2008), os solos argilosos apresentam agregação das partículas de argila, da qual resulta a porosidade intra-agregados, que aumenta o volume do espaço poroso principalmente aqueles poros com diâmetro reduzido. Já a floresta em sucessão secundária apresentou maior teor de argila (827 $\mathrm{g} \mathrm{kg}^{-1}$ ) e consequentemente maior porosidade total. Os altos valores da porosidade total foram observados em ambas as áreas e mostram a influência da floresta nas propriedades físicas do solo. 
Ao avaliar o sistema radicular e propriedades físicas do solo em cafezais com diferentes espaçamentos, Silva e Martins (2010), constataram que o aumento da quantidade de raízes proporcionou maiores valores de porosidade total.

De acordo com Cunha et al. (2011), é de extrema importância a presença de resíduos vegetais depositados no solo, que auxiliam na estruturação do solo e na estabilidade dos agregados em função do acúmulo da matéria orgânica e da intensa atividade biológica que resulta na melhoria da aeração do solo e na infiltração de água influenciando no desenvolvimento do sistema radicular.

A CAT na profundidade de 0,2 - 0,3 diferiu estatisticamente das demais camadas avaliadas, em ambas as áreas. A maior CAT encontrada foi na camada de $0-0,1 \mathrm{~m}\left(0,29 \mathrm{~m}^{3} \mathrm{~m}^{-3}\right)$ na floresta em sucessão secundária (Figura 2F). Já a maior CC foi encontrada na camada de 0,2 - 0,3 $\left(0,49 \mathrm{~m}^{3} \mathrm{~m}^{-3}\right)$ do solo da floresta em regeneração (Figura 2G).

Os indicadores de CAT/PT e CC/PT nas áreas estudadas são apresentados nas figuras 2H e 2I. A maior CAT/PT ocorreu no solo da floresta em sucessão secundária, com valor de 0,38 na camada de 0 - 0,1 m. O menor CAT/PT observado ocorreu na floresta em restauração, sendo esse de 0,19. Pott et al. (2017), encontraram maior valor de CAT/PT na camada de 0 - 0,1 m no solo de uma floresta em processo de regeneração ocupada por espécies florestais nativas.

Reynolds et al. (2002), propôs valores de referência de 0,34 para CAT/PT e 0,66 para CC/PT como parâmetros ideais, indicando que o solo apresenta condições físicas adequadas para crescimento e desenvolvimento das plantas (FIDALSKI et al., 2008). A floresta em restauração apresentou valores de CAT/PT abaixo do limite proposto por Reynolds (2002), sendo 0,23 na camada de 0,1 - 0,2 e 0,19 na camada de 0,2 - 0,3 m. Esse resultado pode estar relacionado com o histórico de uso e ocupação do solo, em função do pisoteio animal que é considerado um dos principais responsáveis pela degradação dos solos, aumentando a sua densidade, microporosidade e resistência à penetração, consequentemente levando a redução da macroporosidade e porosidade total, principalmente nas camadas superficiais (COLLARES et al., 2011; FIDALSKI; ALVES, 2015).

Para a densidade do solo foi observada correlação negativa com a macroporosidade nas três camadas avaliadas (Tabela 2), essa correlação segundo Matias et al. (2009) ocorre porque a densidade do solo

Tabela 2. Correlação das propriedades físicas do solo em área de floresta em sucessão secundária nas camadas de $0-0,1 \mathrm{~m}, 0,1-0,2 \mathrm{~m}$ e $0,2-0,3 \mathrm{~m}$ de profundidade.

Table 2. Correlation of soil physical properties in a forest area in secondary succession in the layers $0-0.1 \mathrm{~m}$, $0.1-0.2 \mathrm{~m}$ and $0.2-0.3 \mathrm{~m}$ depth.

\begin{tabular}{|c|c|c|c|c|c|c|c|}
\hline Propriedades & Map & Mip & PT & CAT & CC & CC/PT & CAT/PT \\
\hline \multicolumn{8}{|c|}{ 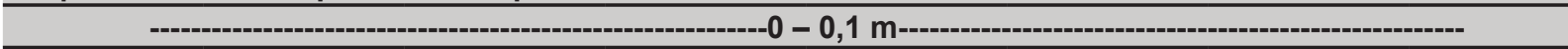 } \\
\hline Ds & $-0,298^{n s}$ & $-0,304^{\mathrm{ns}}$ & $-0,812^{*}$ & $-0,315^{\mathrm{ns}}$ & $-0,252^{n s}$ & $0,151^{\mathrm{ns}}$ & $0,151^{\mathrm{ns}}$ \\
\hline Map & & $-0,756 \mathrm{~ns}$ & 0,642 ns & $0,999^{* *}$ & $-0,790 \mathrm{~ns}$ & $-0,982^{* *}$ & $0,982^{* *}$ \\
\hline Mip & & & $0,015^{\mathrm{ns}}$ & $-0,747^{\mathrm{ns}}$ & $0,998^{* *}$ & $0,864^{*}$ & $-0,864^{*}$ \\
\hline PT & & & & 0,652 ns & $-0,038^{n s}$ & $-0,488 \mathrm{~ns}$ & $0,488^{n s}$ \\
\hline CAT & & & & & $-0,782^{\mathrm{ns}}$ & $-0,979^{* *}$ & $0,979^{* *}$ \\
\hline CC & & & & & & $0,890^{*}$ & $-0,890^{*}$ \\
\hline CC/PT & & & & & & & $-0,999$ ** \\
\hline \multicolumn{8}{|c|}{ 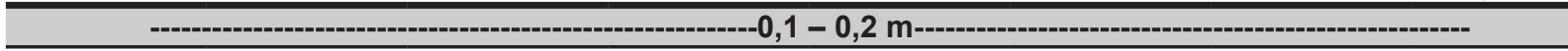 } \\
\hline Ds & $-0,691 \mathrm{~ns}$ & $0,251^{\mathrm{ns}}$ & $-0,676^{\mathrm{ns}}$ & $-0814^{*}$ & $0,734^{\mathrm{ns}}$ & $0,813^{*}$ & $-0,813^{*}$ \\
\hline Map & & $-0,842^{*}$ & $0,091^{\mathrm{ns}}$ & $0,435^{\mathrm{ns}}$ & $-0,743^{n s}$ & $-0,539 \mathrm{~ns}$ & 0,539 ns \\
\hline Mip & & & 0,460 ns & 0,097 ns & $0,405^{\mathrm{ns}}$ & $0,039 \mathrm{~ns}$ & $-0,039 \mathrm{~ns}$ \\
\hline PT & & & & $0,896^{*}$ & $-0,476{ }^{n s}$ & $-0,814^{*}$ & $0,814^{*}$ \\
\hline CAT & & & & & $-0,817^{*}$ & $-0,986^{* *}$ & $0,986^{* *}$ \\
\hline CC & & & & & & $0,896^{*}$ & $-0,896^{*}$ \\
\hline CC/PT & & & & & & & $-0,999$ ** \\
\hline & & & ---0 , & ,3 m----.. & 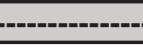 & --1------- & ---- \\
\hline Ds & $-0,862^{*}$ & $0,811^{*}$ & $-0,756^{n s}$ & $-0,850^{*}$ & $0,780^{n s}$ & $0,839^{*}$ & $-0,839^{*}$ \\
\hline Map & & $-0,907^{*}$ & $0,903^{*}$ & $0,999^{* *}$ & $-0,905^{*}$ & $-0,987^{* *}$ & $0,987^{* *}$ \\
\hline Mip & & & $-0,637^{n s}$ & $-0,920^{*}$ & $0,999^{* *}$ & $0,959^{* *}$ & $-0,959^{* *}$ \\
\hline PT & & & & $0,887^{*}$ & $-0,635^{n s}$ & $-0,826^{*}$ & $0,826^{*}$ \\
\hline CAT & & & & & $-0,919^{*}$ & $0,992^{* *}$ & $-0,992^{* *}$ \\
\hline CC & & & & & & $0,959^{* *}$ & $-0,959^{* *}$ \\
\hline CC/PT & & & & & & & $-0,999$ ** \\
\hline
\end{tabular}

* Correlação significativa a 5\% de probabilidade. *** Correlação significativa a I\% de probabilidade. ${ }^{\text {ns. }}$ não significativo. 
é inversamente proporcional à macroporosidade. Houve alta correlação negativa entre a densidade e a porosidade total nas três camadas, corroborado por Conte et al. (2007), de que a porosidade total é inversamente proporcional à densidade do solo, onde os maiores valores de porosidade total correspondem aos menores valores de densidade do solo. Foi observada correlação positiva significativa entre a densidade do solo e a microporosidade apenas na camada de 0,2 - 0,3 m.

$\mathrm{Na}$ floresta em sucessão secundária, a macroporosidade apresentou alta correlação negativa com a microporosidade em todas as camadas estudadas e com a porosidade total na camada de 0,2 - 0,3 m. Quando os valores de porosidade não estão equilibrados entre si, pode haver o estabelecimento da dominação de microporos, causando uma deficiência na oxigenação e fluxo de massa, impedindo o desenvolvimento normal das plantas (BOGNOLA et al., 2010).

A floresta em restauração (Tabela 3) apresentou alta correlação positiva entre a macroporosidade e a porosidade total nas três camadas avaliadas e correlação negativa entre a macroporosidade e microporosidade nas camadas de 0 - 0,1 m e 0,2 - 0,3 m. Houve alta correlação positiva significativa entre a macroporosidade e capacidade de aeração total nas camadas de 0 - 0,1 m e 0,2 - 0,3 m.

Tabela 3. Correlação das propriedades físicas do solo em área de floresta em restauração nas camadas de $0-0,1 \mathrm{~m}$,

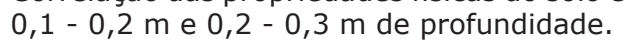

Table 3. Correlation of soil physical properties in an area of forest restoration in the layers of $0-0.1 \mathrm{~m}, 0.1-0.2 \mathrm{~m}$ and $0.2-0.3 \mathrm{~m}$ depth.

\begin{tabular}{|c|c|c|c|c|c|c|c|c|}
\hline Propried & ades & Map & Mip & PT & CAT & CC & CC/PT & CAT/PT \\
\hline \multicolumn{9}{|c|}{ 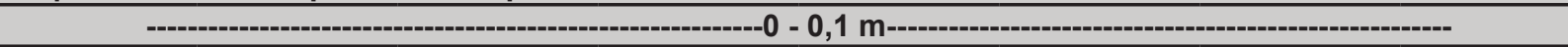 } \\
\hline Ds & & $-0,964^{\star *}$ & $0,842^{*}$ & $-0,786^{n s}$ & $-0,965^{\star *}$ & $0,863^{*}$ & $0,971^{* \star}$ & $-0,971^{* *}$ \\
\hline Map & & & $-0,775^{n s}$ & $0,885^{\star}$ & $0,999^{* *}$ & $-0,793$ ns & $-0,999^{* *}$ & $0,999^{* *}$ \\
\hline Mip & & & & $-0,392 \mathrm{~ns}$ & $-0,758^{n s}$ & $0,998^{* *}$ & $0,787^{\text {ns }}$ & $-0,787^{n s}$ \\
\hline PT & & & & & $0,897^{*}$ & 0,420 ns & $-0,875^{\star}$ & $0,875^{\star}$ \\
\hline CAT & & & & & & $-0,778 \mathrm{~ns}$ & $-0,999^{* *}$ & 0,999** \\
\hline CC & & & & & & & $0,806^{n s}$ & $-0,806^{n s}$ \\
\hline CC/PT & & & & & & & & $-0,999$ ** \\
\hline Ds & & $-0,785$ ns & $0,487^{\mathrm{ns}}$ & $-0,517 \mathrm{~ns}$ & $-0,728$ ns & $0,367^{\text {ns }}$ & $0,738 \mathrm{~ns}$ & $-0,738 \mathrm{~ns}$ \\
\hline Map & & & $-0,304^{n s}$ & $0,828^{*}$ & $0,988^{* *}$ & $-0,299 \mathrm{~ns}$ & $-0,969 * *$ & $0,969^{* *}$ \\
\hline Mip & & & & 0,276 ns & $-0,328 \mathrm{~ns}$ & $0,970^{* *}$ & $0,458 \mathrm{~ns}$ & $-0,458 \mathrm{~ns}$ \\
\hline PT & & & & & $0,806^{\mathrm{ns}}$ & $0,269 \mathrm{~ns}$ & $-0,710^{n s}$ & $0,710^{\mathrm{ns}}$ \\
\hline CAT & & & & & & $-0,353^{n s}$ & $-0,989^{* *}$ & $0,989^{* *}$ \\
\hline CC & & & & & & & 0,486 ns & $-0,486 \mathrm{~ns}$ \\
\hline CC/PT & & & & & & & & $-0,999$ ** \\
\hline & & & & -------0,2 & 3 m--------. & ------------ & -------------- & --- \\
\hline Ds & & $-0,642 \mathrm{~ns}$ & $0,016^{\mathrm{ns}}$ & $-0,995^{\star *}$ & $-0,734$ ns & $0,222^{n s}$ & $0,677^{\mathrm{ns}}$ & $-0,677^{\mathrm{ns}}$ \\
\hline Map & & & $-0,787$ ns & $0,637^{n s}$ & $0,985^{\star *}$ & $-0,883^{*}$ & $-0,993^{* *}$ & $0,993^{* *}$ \\
\hline Mip & & & & $-0,0266^{n s}$ & $-0,689$ ns & $0,969^{* *}$ & 0,746 ns & $-0,746^{\mathrm{ns}}$ \\
\hline PT & & & & & $0,735^{\mathrm{ns}}$ & $-0,219 \mathrm{~ns}$ & $-0,677$ ns & $0,677^{\mathrm{ns}}$ \\
\hline CAT & & & & & & $-0,823^{*}$ & $-0,996^{* *}$ & $0,996^{* *}$ \\
\hline CC & & & & & & & $0,866^{*}$ & $-0,866^{*}$ \\
\hline CC/PT & & & & & & & & $-0,999$ ** \\
\hline
\end{tabular}

* Correlação significativa a 5\% de probabilidade. ** Correlação significativa a I\% de probabilidade. ${ }^{\text {ns. }}$ não significativo.

A densidade do solo apresentou alta correlação positiva com a capacidade de campo e capacidade de armazenamento de água no solo nas camadas de 0,1 - 0,2 m e 0,2 - 0,3 m. A mesma apresentou correlação negativa significativa com a porosidade total nas três camadas avaliadas, pois uma é inversamente proporcional a outra. Foi observada alta correlação positiva entre a porosidade total e a capacidade de aeração total nas três camadas estudadas.

Para a variável resistência à penetração houve diferença entre a área de floresta em sucessão secundária e a floresta em restauração (Figura 3). Assim, maiores valores de resistência à penetração foram observados na floresta em restauração, chegando a 2,02 MPa nas camadas 0,1 - 0,2 m e 0,2 - 0,3 m de profundidade. Estes valores são atribuídos ao sistema de manejo utilizado anteriormente na área, principalmente pela compactação exercida pelo pisoteio animal (TORRES et al., 2012). O valor de 2,0 MPa tem sido aceito como o limite crítico de resistência mecânica do solo à penetração (PEREIRA; THOMAZ, 2015). 


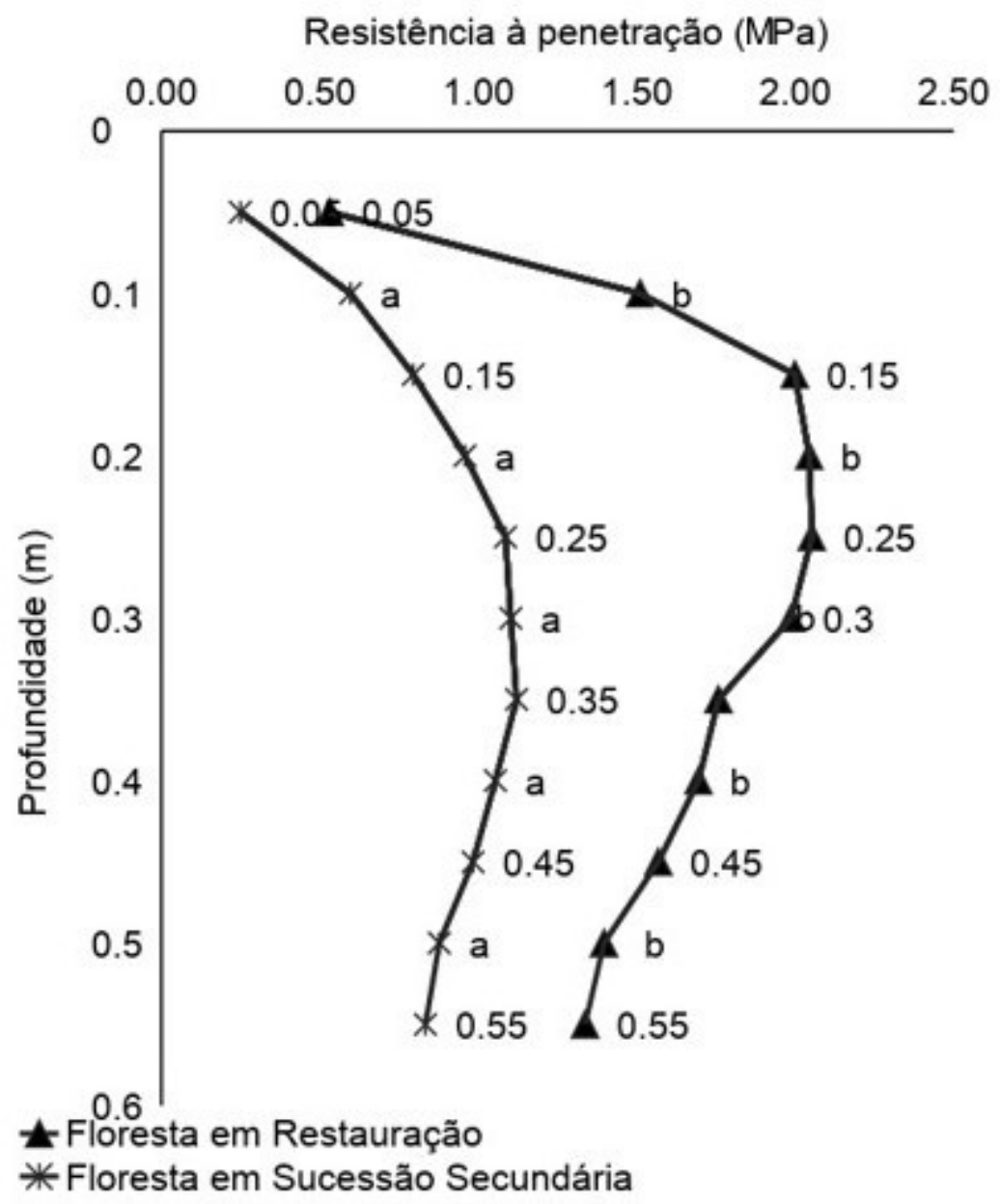

Figura 3. Resistência à penetração (RP) em área de floresta em sucessão secundária e floresta em restauração. Figure 3. Resistance to penetration (PR) in forest area in secondary succession and forest under restoration.

Segundo Silva et al. (2012), valores acima de 2,5 MPa em situações de baixa disponibilidade de água podem restringir ou mesmo impedir o crescimento e o desenvolvimento das raízes. No entanto, Tavares Filho et al. (2001), ressaltam que mesmo que sejam observados valores de resistência à penetração acima dos valores críticos, em situações que existam estruturas que permitam as trocas de difusão do oxigênio, condições químicas e umidade, o desenvolvimento das raízes será mantido através de pontos de menor resistência, todavia, podem apresentar deformações morfológicas. Por outro lado, Carvalho et al. (2004), ao avaliarem propriedades físicas em sistemas agroflorestais, atribuíram a baixa resistência do solo à penetração na profundidade de 0 - 0,1 m devido a incorporação de matéria orgânica resultante desses sistemas.

\section{CONCLUSÃO}

O processo de recuperação de um solo após degradação é lento, passados dez anos o solo sob restauração florestal passiva não se recuperou totalmente, devido às variações principalmente nos teores de matéria orgânica em relação a floresta em sucessão secundária, que influenciam todas as demais propriedades físicas do solo.

A floresta em restauração, apresenta maior densidade do solo e resistência à penetração, menor macroporosidade e porosidade total em relação a floresta em sucessão secundária.

A floresta em sucessão secundária apresentou alta correlação tanto negativa quanto positiva entre as propriedades físicas do solo estudadas e nas três camadas o efeito foi crescente conforme o aumento da profundidade, diferente da floresta em restauração que o efeito foi ao contrário à correlação foi decrescente conforme a profundidade. 


\section{REFERÊNCIAS BIBLIOGRÁFICAS}

AIDE, T. M. Clues for tropical forest restoration. Restoration Ecology, v. 8, n.4, p. 327, 2000.

ABNT - ASSOCIAÇÃO BRASILEIRA DE NORMAS TÉCNICAS. NBR 7182 - Solo-Ensaio de compactação. Rio de Janeiro, 1986.

ALVARES, C. A.; STAPE, J. L.; SENTELHAS, P. C.; MORAES GONÇALVES, L. J.; SPAROVEK, G. Köppen's climate classification map for Brazil. Meteorologische Zeitschrift, v. 22, n. 6, p.711-728, 2013.

ANDREOLA, F.; COSTA, L. M.; OLSZEVSKI, N.; JUCKSCH, I. A cobertura vegetal de inverno e a adubação orgânica e, ou, mineral influenciando a sucessão feijão/milho. Revista Brasileira de Ciência do Solo, v. 24, n. 4, p. 867-874, 2000 .

BOGNOLA, I. A.; DEDECEK, R. A.; LAVORANTI, O. J.; HIGA A. R. Influência de propriedades físico-hídricas do solo no crescimento de Pinus taeda. Pesquisa Florestal Brasileira, v. 30, p. 37-49, 2010.

BORTOLINI, D.; BRAIDA, J. A.; CASSOL, L. C.; MIGLIORINI, F.; SILVA, M. R.; FERRAZZA, J. M. Altura de manejo de papua e propriedades de solo em sistema de integração lavoura - pecuária. Revista Ceres, v. 60, p. 535-543, 2013.

BRADY, N. C.; WEIL, R. R. The nature and properties of soils. 14 ed. New Jersey: Prentice Hall, 2008.

BRAIDA, J. A.; REICHERT, J. M.; VEIGA, M.; REINERT, D. J. Resíduos vegetais na superfície e carbono orgânico do solo e suas relações com a densidade máxima obtida no ensaio de Proctor. Revista Brasileira de Ciência do Solo, v. 30, n. 4, p. 605-614, 2006.

BRASIL. CONAMA - Conselho Nacional de Meio Ambiente. Resolução No 10, de $\mathbf{1}^{\circ}$ de Outubro de 1993. 1993. Disponível em: < http://www.icmbio.gov.br/cepsul/images/stories/legislacao/Resolucao/1993/ res_conama_10_1993_estagiossucessaomataatlantica.pdf >. Acesso em 30 jan. 2018

CALGARO, H. F.; BUZETTI, S.; SILVA, L. R.; STEFANINI, L.; MIRANDA, L. ’P. M. M.; MORAES, M. A.; MORAES, M. L. T. Distribuição natural de espécie arbóreas em áreas com diferentes níveis de antropização e relação com os atributos químicos do solo. Revista Árvore, Viçosa, v. 39, n. 2, p. 233-243, 2015.

CARDOSO, E. V.; SILVA, M. L. N.; CURI, N.; FERREIRA, M. M.; FREITAS, D. A. F. Qualidade química e física do solo sob vegetação arbórea nativa e pastagens no Pantanal Sul-Mato-Grossense. Revista Brasileira de Ciência do Solo, v. 35, n. 2, p. 613-622, 2011.

CARVALHO, R.; GOEDERT, W. J.; ARMANDO, M. S. Atributos físicos da qualidade de um solo sob sistema agroflorestal. Pesquisa Agropecuária Brasileira, Brasília, v. 39, n. 11, p. 1153-1155, 2004.

COLLARES, G. L.; REINERT, D. J.; REICHERT, J. M.; KAISER, D. R. Compactação superficial de Latossolos sob integração lavoura: pecuária de leite no noroeste do Rio Grande do Sul. Ciência Rural, v. 41, n. 2, p. 246- 250, 2011.

CONTE, O.; LEVIEN, R.; TREIN, C. R.; CEPIK, C. T. C.; DEBIASI, H. Demanda de tração em haste sulcadora na integração lavoura pecuária com diferentes pressões de pastejo e sua relação com o estado de compactação do solo. Revista Engenharia Agrícola, v. 27, n. 1, p. 220-228, 2007.

COUTINHO, F. S.; PEREIRA, M. G.; MENEZES, C. E. G.; GUARESCHI, R. F.; ASSUNÇÃO, S. A. Atributos Edáficos em Áreas de Agricultura, Pastagem e Três Estágios Sucessionais de Floresta. Floresta Ambiente, v. 24, e00091914, 2017.

CUNHA, E. Q.; STONE, L. F.; MOREIRA, J. A. A.; FERREIRA, E. P. B.; DIDONET, A. D.; LEANDRO, W. M. Sistemas de preparo do solo e culturas de cobertura na produção orgânica de feijão e milho. I - Atributos físicos do solo. Revista Brasileira de Ciência do Solo, v. 35, p. 589- 602, 2011.

EMBRAPA - EMPRESA BRASILEIRA DE PESQUISA AGROPECUÁRIA. Centro Nacional de pesquisa de solos. Manual de métodos de análise de solo. 2 a ed. Rio de Janeiro: Embrapa, 2011, 230 p.

FIDALSKI, J.; ALVES, S. J. Altura de pastejo de braquiária e carga animal limitada pelos atributos físicos do solo em sistema integração lavoura-pecuária com Soja. Revista Brasileira de Ciência do Solo, v. 39, n. 3, p. 864-870, 2015.

Sci. For., Piracicaba, v. 47, n. 124, p. 696-707, dez. 2019

DOI: doi.org/10.18671/scifor.v47n124.11 
Bertolini et al. - Propriedades físicas de solo em Floresta Ombrófila Mista sob

processo de restauração passiva

FIDALSKI, J.; TORMENA, C. A.; CECATO, U.; LUGÃO, S. M. B.; BARBERO, L. M.; COSTA, M. A. T. Qualidade física do solo em pastagem adubada e sob pastejo contínuo. Pesquisa Agropecuária Brasileira, v. 43, n. 11, p. 1583-1590, 2008.

HAMZA, M. A.; ANDERSON, W. K. Soil compaction in cropping systems: A review of the nature, causes and possible solutions. Soil and tillage research, v. 82, n. 2, p. 121-145, 2005.

HICKMANN, C.; COSTA, L. M.; SCHAEFER, C. E. G. R.; FERNANDES, R. B. A.; ANDRADE, C. L. T. Atributos físico-hidricos e carbono orgânico de um argissolo após 23 anos de diferentes manejos. Revista Caatinga, v. 25, n. 1, p.128-136, 2012.

IBGE - INSTITUTO BRASILEIRO DE GEOGRAFIA E ESTATÍSTICA. Manual Técnico da Vegetação Brasileira. Rio de Janeiro: IBGE, 2012. (Série Manuais Técnicos em Geociências)

KLEIN, V. A. Física do solo. 3 ed. Passo Fundo: Editora UPF, 2014.

KLEIN, V. A. Densidade relativa - um indicador da qualidade física de um latossolo vermelho. Revista de Ciências Agroveterinárias, Lages, v. 5, n. 1, p. 26 -32, 2006.

LUCIANO, R. V.; ALBUQUERQUE, J. A.; DA COSTA, A.; BATISTELlA, B.; WARMLING, M. T. Atributos físicos relacionados à compactação de solos sob vegetação nativa em região de altitude no Sul do Brasil. Revista Brasileira de Ciência do Solo, v. 36, n. 6, 2012.

MARCOLIN, C. D.; KLEIN, V. A. Determinação da densidade relativa do solo por uma função de pedotransferência para a densidade do solo máxima. Acta Scientiarum. Agronomy, v. 33, n. 2, 2011.

MARTINS, S. V. Recuperação de Matas Ciliares, ed. 2. Viçosa: Aprenda Fácil, 2014. 220 p.

MATIAS, S. S. R.; BORBA, J. A.; TICELLI, M.; PANOSSO, A. R.; CAMARA, F. T. Atributos físicos de um Latossolo Vermelho submetido a diferentes usos. Revista Ciência Agronômica. v. 40, p. 331-338, 2009.

MENEZES, C. E. G.; CORREIA, M. E. F.; PEREIRA, M. G.; BATISTA, I.; RODRIGUES, K. M.; COUTO, W.H. Macrofauna edáfica em estágios sucessionais de floresta estacional semidecidual e pastagem mista em Pinheiral (RJ). Revista Brasileira de Ciência do Solo, v. 33, n. 6, p. 1647-1656, 2009.

MICHALOWICZ, L. Atributos químicos do solo e resposta da sucessão milho-cevada-feijão trigo influenciados por doses e parcelamento de gesso em Plantio Direto. 2012. 52 p. Dissertação (Mestrado em Agronomia) - Universidade Estadual do Centro Oeste, Guarapuava, 2012.

PEREIRA, A. A.; THOMAZ, E. L. Parâmetros físicos do solo em diferentes sistemas de manejo convencional, Município de Reserva - PR. Revista do Departamento de Geografia, v. 30, p. 65 - 76, 2015.

POTT, C. A.; ZERBIELLI, L. C.; MARTINS, P. J.; GARDIN, E.; GARCIA, M. L. Qualidade física do solo em sistemas florestais, pecuários e integrados de produção. Brazilian Journal of Applied Technology for Agricultural Science, v. 10, n. 2, 2017.

REICHERT, J. M.; SUZUKI, L. E. A. S.; REINERT, D. J. Compactação do solo em sistemas agropecuários e florestais: identificação, efeitos, limites críticos e mitigação. Tópicos em ciência do solo, v. 5, p. 49-134, 2007.

REINERT, D. J.; ALBUQUERQUE, J. A.; REICHERT, J. M.; AITA, C.; ANDRADA, M. M. C. Limites críticos de densidade do solo para o crescimento de raízes de plantas de cobertura em argissolo vermelho. Revista Brasileira de Ciência do Solo, Viçosa. v. 32, p. 1805-1816, 2008.

REIS, A.; BECHARA, F. C.; TRES, D. R.; TRENTIN, B. E. Nucleação: concepção biocêntrica para a restauração ecológica. Ciência Florestal, v. 24, n. 2, p. 509-519, 2014.

REYNOLDS, W. D.; BOWMAN, B. T.; DRURY, C. F.; TAN, C. S.; LUC, X. Indicators of good soil physical quality: density and storage parameters. Geoderma, v. 110, n. 1, p. 131-146, 2002.

SERENGIL, Y.; GOKBULAK, F.; OZHAN, S.; HYZAL, A.; SENGONUL, K.; BALC, A.; OZYUVACI, N. Hydrological impacts of a slight thinning treatment in a deciduous forest ecosystem in Turkey. Journal of Hidrology, $\mathrm{v}$. 333, p. 569-577, 2007.

SILVA, A. R.; SILVA, L. L.; FRAZÃO, J. J.; SALGADO, F. H. M.; SILVA, M. C.; CORRECHER, V. Resistência mecânica à penetração do solo com diferentes coberturas vegetais sob sistema. Revista Científica Eletrônica de Agronomia, Garça, v. 22, n. 2, 2012. 
SILVA, D. C.; SILVA, M. L. N.; CURI, N. OLIVEIRA, A. H.; SOUZA, F. S.; MARTINS, S. G.; MACEDO, R. L. Atributos do solo em sistemas agroflorestais, cultivo convencional e floresta nativa. Revista de Estudos Ambientais, v. 13, n. 1, p. 77-86, 2011.

SILVA, V.; L. B.; MARTINS, P. F. S. Propriedades físicas do solo e sistema radicular do cafeeiro, variedade conilon, sob diferentes espaçamentos. Revista Ciências Agrárias, v. 53, n. 1, p. 96-101, 2010.

SILVA, M. B.; KLIEMANN, H. J.; SILVEIRA, P. M.; LANNA, A. C. Atributos biológicos do solo sob influência da cobertura vegetal e do sistema de manejo. Pesquisa Agropecuária Brasileira, v. 42, n. 12, p. 1755-1761, 2007.

SPERA, S. T. DENARDIN, J. E.; ESCOSTEGUY, P. A. V.; SANTOS, H. P.; FIGUEROA. E. A.Dispersão de argila em microagregados de solo incubado com calcário. Revista Brasileira Ciência do Solo, v. 32, p. 2613-2620, 2008.

TAVARES FILHO, J.; BARBOSA, G. M. C.; GUIMARÃES, M. F.; FONSECA, I. C. B. Resistência do solo à penetração e desenvolvimento do sistema radicular de milho (Zea mays) sob diferentes sistemas de manejo em um Latossolo Roxo. Revista Brasileira de Ciência do Solo, v. 25, p. 725-730, 2001.

THOMAZ, E. L.; VESTENA, L. R. Aspectos climáticos de Guarapuava - PR. Guarapuava: Ed. UNICENTRO, 2003. 106p.

TORRES, J. L. R.; RODRIGUES Junior, D.J.; SENE, G.A.; JAIME, D.G.; VIEIRA, D.M.S. Resistência a penetração em área de pastagem de capim Tifton, influenciada pelo pisoteio e irrigação. Bioscience Journal, Uberlândia, v. 28 , p. $232-239,2012$.

TRENTIN, B. E.; ESTEVAN, D. A.; ROSSETTO, E. F. S.; GORENSTEIN, M. R.; BRIZOLA, G. P.; BECHARA, F. C. Restauração florestal na Mata Atlântica: passiva, nucleação e plantio de alta diversidade. Ciência Florestal, v. 28, n. 1, p. 160-174, 2018.

Recebido em: 28/02/2018

Aceito em: 25/03/2019 